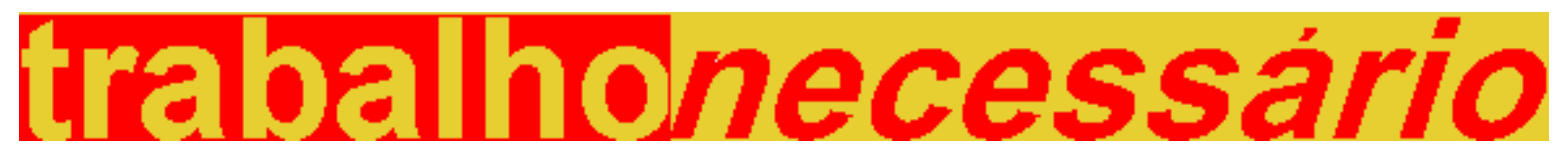

iss $\mathrm{n:} 1808-799 \mathrm{X}$

ano 2 - número 2 - 2004

\title{
SOCIEDADE, EDUCAÇÃO, TECNOLOGIA E OS USOS DAS TIC[1] NOS PROCESSOS EDUCATIVOS[2]
}

\author{
Henrique Moura Dante[3]
}

\section{Uma aproximação à questão}

As relações entre o homem e o meio sempre foram mediadas pelas tecnologias vigentes em cada momento histórico. Desta forma, elas tiveram um papel fundamental na revolução agrária, a qual fixou o homem a um espaço geográfico, movido pela possibilidade de semear a terra. Assim, deixamos de ser nômades. Este fato não teria sido consumado sem as ferramentas criadas pelos humanos. A idéia original foi utilizar as tecnologias com o objetivo de mediar as relações humanas com a natureza para proporcionar melhorias no bem estar coletivo. Entretanto, a medida que nos fixamos para semear a terra e que nos mantivemos em um mesmo lugar por longos períodos de tempo, começou a exploração da natureza pela humanidade, materializada, nesse caso, pelo esgotamento do solo.

$\mathrm{Na}$ Revolução Industrial, que ao longo do tempo foi concentrando a humanidade em grandes cidades, o uso das tecnologias assumiu conotações mais fortes. Entre todas as transformações introduzidas nas relações sociais e no modo de vida das pessoas de uma forma geral, merece destaque, o surgimento da classe operária e a conseqüente perda que tiveram os artesãos de suas ferramentas de trabalho (tecnologias), pois essas tornaram-se "obsoletas" por não mais servir aos novos modos de produção. Como resultado, o trabalhador (artesão) deixou de conhecer todo o processo de fabricação dos produtos que manufaturava (conhecimento geral e amplo) para ser um operário fabril, com qualificação apenas para inserir uma 
determinada peça em um lugar específico e predefinido por outro (conhecimento restrito e "especializado"). A sociedade atual é caracterizada por múltiplas denominações, como a sociedade em rede (Castells, 1997), a revolução semiótica (Dieterich, 1999), além de outros termos mais utilizados como sociedade pósmoderna, sociedade da aprendizagem, sociedade da informação, sociedade do conhecimento e muitíssimas outras adjetivações, mas o importante é que, qualquer que seja a denominação, sua "marca registrada" é a compressão do tempo e do espaço, as quais viabiliza o rápido avanço da globalização econômica, que potencializa cada vez mais a separação entre os que têm acesso aos bens produzidos por esse modelo sócio-econômico daqueles que estão à margem desse processo. Para isto contribui significativamente, as tecnologias da informação e da comunicação - TIC.

Neste sentido, não podemos aprofundar nossa discussão sem buscar um maior entendimento sobre as relações entre os avanços tecnológicos e o modelo social e econômico vigente.

\section{As tecnologias e a sociedade globalizada economicamente}

A atual fase de incessantes avanços tecnológicos é, ao mesmo tempo, causa e resultado de mudanças na forma de vida das pessoas. Eles provocam essas mudanças porque os produtos são lançados no mercado com o objetivo de gerar novas necessidades (de consumo, geralmente) nas pessoas, as quais, por sua vez, suscitam novas necessidades de avanços tecnológicos. Esse efeito se repete em uma espiral ascendente, cujo limite é apenas o poder de compra dos mercados. Sob essa lógica, as tecnologias têm papel fundamental no fortalecimento dos mercados.

Vários exemplos da cadeia evolutiva de alguns produtos podem ser citados para esclarecer essas afirmações, mas é perfeitamente possível fazê-lo com apenas um. Optamos pelo telefone celular. A humanidade vivia sem esse aparelho até pouco tempo atrás em uma situação em que as parcelas incluídas das sociedades (em todo o planeta) já tinham suas necessidades básicas satisfeitas. Nessa perspectiva, a economia de mercado necessitava, e continua necessitando, criar constantemente produtos para gerar novas necessidade, mas não básicas, apenas consumo (é necessário compreender que esse processo ocorre simultaneamente com uma grande quantidade de novos produtos tecnológicos). Assim, surge o celular. Uma vez criado, chega ao mercado depois de uma eficiente campanha publicitária. As pessoas começam a comprá-lo. Inicialmente um bem de consumo caro - privilégio de poucos. Paralelamente, a publicidade intensifica a divulgação de suas infinitas vantagens. Assim, muita gente quer comprá-lo, tem um forte desejo de possuí-lo, pois é algo que diferencia os que possuem. É um elemento que confere status. Estrategicamente, os preços baixam um pouco e aqueles que o desejavam, mas não podiam adquiri-lo, passam a poder fazê-lo, pois agora o preço está ao alcance da classe média.

Em seguida, quando grande parte dos consumidores potenciais ao longo da geografia do planeta já adquiriu seu aparelho, surgiram e continuam surgindo as melhorias tecnológicas possíveis. Claro, aquele modelo que um indivíduo tem (que há pouco tempo era uma maravilha) já não serve mais, está obsoleto. No caso dos celulares, esse ciclo começou pelas baterias (as primeiras tinham pouca autonomia), depois veio a redução do tamanho, a conexão à internet, entre outros. A cada novo "avanço" corresponde uma nova necessidade criada nos consumidores e cada compra gera a necessidade de um novo "avanço". É necessário suscitar novas necessidades para mover o mercado, pois a espiral não pode deixar de crescer em nome do bemestar da economia mundial (mais adiante se comentará os limites do termo mundial aqui utilizado).

Evidentemente, essa lógica é perfeitamente transferível a muitos outros produtos, portanto, a partir desse 
exemplo se pode visualizar a lógica da mundialização dos mercados desde a criação das necessidades de consumo.

O problema é que só participam dessa overdose de consumo aqueles segmentos (minoritários) da população considerados incluídos, os demais ficam fora de qualquer possibilidade de acesso.

Portanto, a questão deve ser discutida em torno do fato de que essas diferenças não foram construídas aleatoriamente, nem foram os excluídos que contribuíram para esse quadro. A origem está justamente no pólo oposto, ou seja, a elevada concentração de riquezas nas mãos de poucos. Na Tabela 1, apresentamos um quadro que nos ajuda a compreender melhor essa questão.

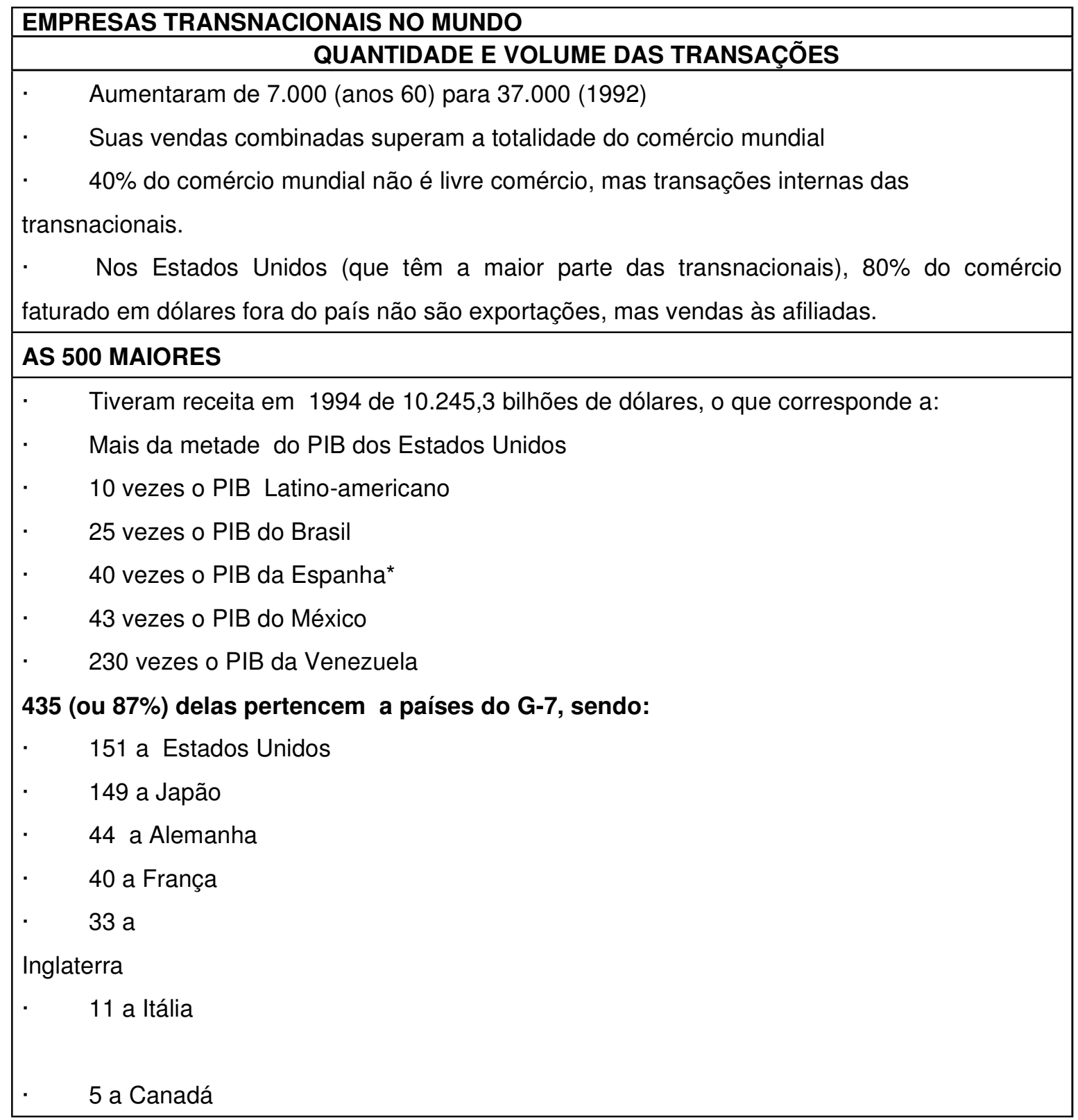

Tabela 1 - As grandes empresas transnacionais

Fonte: Elaboração nossa a partir de Chomsky e Dieterich (1999)

* A partir de http://www.cma.net/camara/esppib.htm

Evidentemente, a partir desse quadro é fácil entender que nem todos participam igualmente dos benefícios decorrentes do fenômeno global. Ao contrário, é necessário que as nações interessadas em gozar deles cumpram algumas exigências (Bautista, 1998):

a) Alto crescimento econômico, conseguido, entre outros aspectos, por um mundo do trabalho

file://C:LDocuments and Settings\AdministradorlMeus documentos\Minhas Webs\NED... 28/8/2008 
flexível, o que o faz competitivo;

b) Escassa coesão social: individualização, dependência e isolamento dos membros de uma sociedade que tem como conseqüência a aceitação das regras do jogo;

c)

Regime político forte. Controle do estado sobre o indivíduo.

A partir desses critérios de inclusão (ou melhor dito, de exclusão) evidentemente existem os que estão dentro (a minoria) e os que estão fora (a maioria). Neste sentido, o termo mundial restringe-se a um grupo seleto de cidadãos e países. Os demais permanecem fora, pois a competitividade do mercado pressupõe fortes e fracos, perdedores e ganhadores (Ramonet, 1997, apud Bautista, 1998 e Castells, 1997). Entretanto, a idéia de ficar fora desse contexto globalizado resulta numa carga tão negativa de "culpabilidade" que as nações (governos) mais pobres fazem "qualquer negócio" para inserir-se, ainda que essa pseudo-inserção resulte em mais sacrifício para suas respectivas sociedades.

Para a consolidação e maximização do cenário descrito, as tecnologias da informação e da comunicação TIC, atualmente, são fundamentais. Essas tecnologias cumprem funções importantes, quais sejam:

a) Transmitir informação de forma rápida (comprimindo o tempo e o espaço), com o fim de manter o crescimento econômico;

b) Individualizar ou isolar e entreter a homens e mulheres de um Estado para manter uma escassa coesão social que, desde o ponto de vista dos interesses do mercado, supõe uma aceitável estabilidade no trabalho e, conseqüentemente, um bom lugar para implantar-se e desenvolver-se;

c) Controlar e governar um Estado, mediante o uso da tecnologia como elemento de legislação ou como ferramenta criadora de dependências psicossociais.

Neste trabalho, vamos analisar as duas primeiras funções, devido a sua relação mais direta com o âmbito educativo. A primeira está mais fortemente relacionada com a essência da globalização dos mercados. São as TIC que fazem com que a informação esteja em todo o planeta ao mesmo tempo, tornando interdependentes as economias dos mais variados países nos distintos continentes.

Esse fluxo financeiro ocorre sem o conhecimento dos governos nacionais, sobretudo, nos países periféricos. A conseqüência mais significativa é o surgimento do denominado "Estado desbordado", "devido à transnacionalização financeira, à informação transmitida por satélite e às práticas das empresas" (Dollfus, 1999). O Estado não tem controle nem influencia nas decisões sobre os fluxos de capital de uma nação a outra ou de um setor econômico a outro, principalmente naqueles países que estão fora da Tabela 1.

Nesse contexto, o estado se debilita; prevalecem as políticas liberais de desregulamentação da economia; diminuem os investimentos nos setores sociais como educação, saúde e segurança públicas, entre outros; são privatizadas as empresas públicas sob o argumento de que a iniciativa privada faz melhor e mais rápido.

Mas temos que nos perguntar, que valores e interesses movem essas empresas? Que benefícios sociais estão produzindo essas mudanças? Em que tipo de distribuição de riqueza está resultando? As respostas estão na Tabela 1.

O desemprego massivo é uma conseqüência dessa função (compressão do tempo e do espaço) das novas tecnologias que atinge todo o planeta. Os produtos são produzidos mais rapidamente e com menos interferência humana, por isso, o emprego é deslocado das atividades secundárias e primárias da economia para a prestação de serviços e para o comércio[4]. Entretanto, esse deslocamento não ocorreu de forma 
linear. No trânsito de uns setores a outros, muita gente ficou fora do mercado em todo o planeta. Na União Européia, por exemplo, existem atualmente cerca de 18 milhões de desempregados (García, 2000). Isso ocorre porque a quantidade de empregos gerados pela prestação de serviços não é suficiente para receber todos que perdem seus postos de trabalhos em decorrência da automatização da produção. Até na própria prestação de serviços, a automatização gera muito desemprego e, em alguns casos, como no sistema bancário, está dizimando a própria categoria profissional. O resultado é muito claro: o desemprego estrutural na sociedade globalizada economicamente.

Um fenômeno mais complexo ocorre nas sociedades dos países "em desenvolvimento". Com certa parcela da população ocorre algo semelhante ao que sucede no primeiro mundo, já caracterizado anteriormente, devendo-se considerar o fato agravante de que esses países continuam com elevados índices de crescimento populacional, enquanto no primeiro esse aumento é mínimo ou, inclusive, nulo ou negativo em alguns casos. Não obstante, o problema é ainda mais grave em outras camadas da população. No outro pólo, e como conseqüência mais negativa das diferenças sociais brutais enfrentadas por esses países, se encontram verdadeiros bolsões de miséria. Esses grupos estão imersos no desemprego, na fome e na marginalidade como fruto da mais absoluta falta de alternativa econômica digna de sobrevivência, o que gera um ciclo que cresce numa espiral negativa. Não existem condições mínimas de vida digna, como habitação, saúde, educação e segurança, por falta de investimentos dos respectivos governos, pois grande parte dos orçamentos estão destinados ao pagamento das dívidas com os organismos econômicos internacionais. As empresas não se instalam nessas regiões porque não existem infraestrutura e trabalhadores qualificados, 0 que alimenta os ciclos negativos de miséria.

Como conseqüência da falta de alternativa econômica, os indivíduos se deslocam para as grandes urbes em busca de alguma atividade, mas acabam reforçando os coletivos de desempregados e a marginalidade. Ainda é necessário acrescentar que é exatamente nessas camadas mais desfavorecidas da sociedade que se encontram as taxas de natalidade mais elevadas.

Infelizmente, esse cenário é coerente com a lógica do mercado global. Esses coletivos excluídos constituem a "população precária" (Dieterich, 1999). Esta população tem um papel relevante ao constituir-se em um exército de reserva e contribuir para exercer uma constante pressão de baixa sobre os salários dos que têm emprego e funcionar como armazém humano para equilibrar as oscilações conjunturais da demanda de mão de obra. Nesse sentido, afrima Dieterich (1999), ao criticar a lógica do mercado:

"Enquanto a população precária tiver uma proporção adequada frente à população ocupada, as condições reais de vida de seus integrantes não importam: podem, efetiva e literalmente, morrerem de fome. Ter uma proporção adequada quer dizer, nesse contexto, que deve oscilar dentro de um intervalo, determinado por valores limites:

a) que devem ser o suficientemente grande para não afetar negativamente as taxas de lucro; que devem manter a taxa de desemprego natural; ...

b) que têm que ser o suficientemente pequeno para não pôr em perigo a estabilidade política e a coesão social do sistema." Dieterich (1999, 110 e 119)

E, em seguida, conclui:

"Desde o ponto de vista do capital, essa população precária é uma população supérflua, economicamente inviável, cuja educação não produz benefícios - apenas custos para os amos da sociedade global: reduz-se, em conseqüência, a importância dos sistemas educativos formais e gerais " Dieterich (1999, 110 e 119) 
A segunda função das TIC, emanada da lógica do mercado, é individualizar ou isolar e distrair homens e mulheres de um estado para manter escassa a coesão social. Para isso, é necessário proporcionar uma aceitável estabilidade no emprego e potencializar necessidades individuais de consumo, o que gera, de um lado, um ambiente propício para se implantar e desenvolver um pensamento individualista, e, por outro, resulta, evidentemente, em diminuição da coesão social, pois se os interesses são individualizados o povo não tem ideais comuns e, portanto, não vai pressionar o sistema na busca de mudanças e benefícios coletivos para a sociedade.

Quando falamos em coesão social, nos referimos à união do povo em torno a objetivos e ideais comuns de melhoria coletiva da qualidade de vida da população. Entretanto, a elevação desse grau de coesão pode ameaçar a estabilidade do sistema. Dessa forma, a lógica de mercado tem que mantê-la sob controle, em níveis adequados que garantam a estabilidade da "livre economia". O intrigante é que os defensores mais radicais da economia de mercado também advogam pela coesão social. Só que, para eles, isso significa que os humanos tenham suas necessidades atendidas individualmente, isoladamente e, portanto, não exerçam pressão por mudanças orientadas ao atendimento das necessidades sociais e coletivas.

Diante de todo esse contexto, podemos sintetizar algumas características marcantes da globalização econômica:

a) O Estado como ator coadjuvante (principalmente nos países periféricos);

b) A busca desmedida pelo fortalecimento dos mercados em detrimento das prioridades sociais;

c) A multiculturalidade e a interculturalidade através de um complexo processo de intercâmbio de indivíduos, coletividades, nações e nacionalidades, que produzem contraditoriamente, de um lado, a interdependência e a integração, e, de outro, a fragmentação e o antagonismo (CEFET-RN, 1999);

d) As transformações científico-tecnológicas atingem todas as atividades humanas na grande maioria dos países do mundo, de forma que a tecnologia é assumida como um valor positivo, gerando a hegemonia da racionalidade tecnológica sobre a racionalidade ética. Essa racionalidade passa a organizar o mundo com base na razão instrumental e nos princípios da produtividade, lucratividade e qualidade (CEFET$\mathrm{RN}, 1999)$;

e) A tecnologia subordinada à lógica do mercado, reduz o trabalho humano, intensifica o ritmo de trabalho, assegura o aumento da produção, da produtividade e do valor agregado a produtos e serviços, constituindo-se por, essa via, em um poder social;

f) Concentração de riqueza;

g) Precarização do emprego e das relações de trabalho.

Apesar dessas dificuldades, alguns avanços importantes emergem desse contexto. Sem voltar muito no tempo, basta olhar em direção ao princípio do século XX para constatar a melhoria dos índices de qualidade de vida de parcela significativa da humanidade, ocorrida ao longo desses cem anos, e perceber que elas estão vinculadas, em grande parte, às novas tecnologias.

$\mathrm{Na}$ medicina os avanços tecnológicos (eletricidade, eletrônica, microeletrônica, informática, telecomunicações, além dos próprios da medicina) produziram transformações que estão diretamente relacionados com o aumento da expectativa de vida da população. A eletricidade proporcionou uma imensa quantidade de comodidades nos lares. Solucionou problemas como aquecimento, refrigeração, viabilizou o 
fornecimento de água com boa qualidade, entre muitos outros. O acesso à educação foi ampliado em quase todo o planeta. Se continuássemos essa análise dos avanços tecnológicos nas distintas áreas do conhecimento, encontraríamos outras grandes contribuições para a melhoria de qualidade da vida humana.

Ocorre que, infelizmente, esses benefícios não são distribuídos indistintamente a todos os cidadãos e nações. Existem os que têm direito a eles e os que não o têm . Então, o que fazer desde o âmbito educativo, em geral, e da educação profissional, em particular? Aceitar essa situação com resignação? Algo precisa ser feito. Inicialmente, faz-se necessário situar bem o papel da educação na atual sociedade.

Em busca de um papel para a educação

Os discursos sobre a educação para o desenvolvimento, fundamentados na teoria do capital humano, expressam a idéia - quase um lugar comum - de que a educação está univocamente vinculada ao desenvolvimento econômico, ou seja, se há alto nível educacional, há mais desenvolvimento econômico. Dito de outra forma: a educação é responsável pelo desenvolvimento econômico. Se esta relação fosse verdadeira, a educação seria responsável pelo desemprego estrutural do primeiro mundo ou pela miséria do terceiro. Evidentemente, essa não é uma afirmação correta. Nesse sentido, a seguinte contribuição corrobora essa idéia:

"É certamente demagógico afirmar que a miséria latino-americana seja o resultado da deficiente educação do subcontinente, quando há uma série de variáveis determinantes de igual ou maior importância, como são: a dívida externa; a corrupção das elites; o protecionismo do primeiro mundo que se beneficia dez vezes mais do que lhe dá em termos de ajuda; ..." (Dieterich, 1999:87).

Obviamente o papel da educação é muito importante, mas não se lhe pode atribuir um poder inexistente, pois a atuação isolada desde essa esfera não tem o poder de resolver os grandes problemas socioeconômicos do planeta (Frigotto, 1999). Entretanto, para que desde o âmbito educativo se contribua para a construção de mudanças significativas no modelo social vigente é necessário (com muita clareza a respeito de as limitações):

a) Abandonar o enfoque que atribui os insucessos educacionais, exclusivamente, às Reformas e Contra-reformas e seus efeitos: rigidez da legislação, instabilidade nas políticas e crise econômica nos investimentos na educação, pois aos educadores e educadoras ainda lhes resta o controle de importantes condições internas do processo ensino-aprendizagem. Condições sólidas, que repercutem diretamente sobre elementos como método, avaliação, conteúdo, qualidade dos processos e dos resultados (Cabello, 1998);

b) Contribuir para que se estabeleça um verdadeiro diálogo social (e nele inserir-se), do qual têm que participar distintos pontos de vista, como o da sociologia, das ciências da educação, da psicologia, da economia, da organização empresarial, dos sindicatos de empregados e empregadores, além de outros atores sociais que integram a sociedade civil organizada. Desta forma, existe alguma possibilidade de êxito (mas não a garantia), porém sem sua consolidação, seguramente, se manterá a realidade vigente, em que os interesses dos atores que detêm o poder econômico prevalecem sobre os demais.

Esse diálogo deve estar orientado a:

a) Contribuir para a conscientização (Freire, 1980) dos indivíduos / coletivos, instituições e da sociedade em geral sobre essa realidade. Esse processo deve ser o pilar básico para que se construa um gradual processo de transformação social, sem perder de 
vista todas as limitações, obstáculos e possibilidades existentes;

b) Capacitar a organização e, em conseqüência, os docentes e toda a comunidade educacional para mover-se fora do centro da cultura dominante, aproximar-se a ela para entendê-la, processá-la e analisá-la de maneira crítica, juntamente com os estudantes, a fim de ajudá-los a descobrir e entender os processos de construção social presentes na sociedade em que vivem (pedagogia fronteiriça da resistência pós-moderna, Giroux e Aronowitz, 1990, apud Coronel Llamas, 1998);

c) Fortalecer a racionalidade ética frente à racionalidade tecnológica;

d) Impulsionar o uso social das tecnologias (CEFET-RN, 1999);

e) Promover o desenvolvimento e a consolidação de uma concepção de educação profissional que contemple as funções reprodutora e transformadora da educação, ou seja, que proporcione, em todas as ofertas educativas dos distintos níveis e ciclos, uma sólida formação técnica e humanística dos diferentes grupos destinatários;

f) Buscar os meios de fazer com que o trabalho guarde ou reencontre a capacidade de integrar na vida coletiva os que hoje se vêem diante de um processo que os conduz à exclusão social (CEFET-RN, 1999);

g) Deslocar o conceito de empregabilidade da responsabilidade do individuo para o de construção social, da qual devem participar, no mínimo, os indivíduos / coletivos, as empresas, os poderes públicos e as entidades de classe (DIEESE, 2002);

h) Potencializar o uso crítico das TIC nos processos educacionais.

\section{O uso crítico das TIC nos processos educativos}

É imprescindível trazer para dentro da organização escolar uma profunda reflexão sobre essa problemática, já que atualmente essas tecnologias são utilizadas sem uma maior preocupação com suas verdadeiras possibilidades pedagógicas, limitações e riscos associados a esses usos. Ainda não existe uma discussão a respeito das possibilidades e riscos do uso das TIC nos processos educacionais, de forma que também não há uma discussão mais profunda sobre as necessidades de capacitação docente nesse campo. Dessa forma, entre os que utilizam essas ferramentas predomina a idéia de que são meras ferramentas e como tal podem ser utilizadas para o "bem" e para o "mal", conforme se queira.

Não é bem assim. Inicialmente, é importante ter claro que tanto as TIC como as outras tecnologias não são neutras nem são criadas, em princípio, com fins educativos. Na verdade, são desenvolvidas para cumprir outros fins na sociedade e, desde o âmbito educativo, tentamos nos apropriar dessas tecnologias incorporando-as aos processos educacionais.

Exatamente por essa origem as TIC trazem implícitos uns usos que podem não ser coerentes com os fins educativos. Desafortunadamente, em geral, se faz a transposição delas ao ambiente educativo sem que se reflita mais profundamente sobre possíveis incompatibilidades ou outros tipos de implicações. As denominadas TIC, quase todas relacionadas com os últimos avanços tecnológicos que conjugam em alguns equipamentos a capacidade de gravar ou reproduzir a imagem, o som, os textos, e, além disso, conectá-los a um computador e enviar os dados armazenados via internet ou simplesmente aceder a dados gerados por outros são, via de regra, valorizados positivamente pela sociedade (Bautista, 1998). 
Assim, todas as atividades humanas buscam a incorporação dessas tecnologias como forma de estar em dia com os últimos avanços. Acontece que muitas vezes não se reflete sobre as verdadeiras possibilidades e melhoras que podem decorrer dessas incorporações, como também os riscos que elas podem representar (Accino, 2000). Existe na atual sociedade um desmedido consumo dessas tecnologias porque, em geral, não existe consciência sobre as funções que elas cumprem no modelo econômico-social vigente. Isso se torna mais grave ainda quando essa falta de compreensão ocorre no campo educativo, responsável pela formação dos cidadãos para uma profissão e para a participação social, política e cultural, para o lazer e o ócio, enfim para a cidadania.

Como ponto de partida abordaremos o caráter elitista do uso das TIC na educação, que contribui para que os coletivos que têm acesso a elas (a minoria) através da própria formação tenham vantagem sobre os que não têm (a maioria). Isso aumenta ainda mais a discrepância que existe em termos de oportunidades de inclusão social. Evidentemente, a inclusão/exclusão social não pode ser atribuída exclusivamente ao fato de ter ou não acesso às TIC. O problema é que os que têm esse direito também têm muitas outras vantagens com relação aos que não têm e isso contribui para aumentar a distância entre os incluídos e os excluídos.

Feito esse esclarecimento inicial, podemos analisar as possibilidades de utilização das TIC por aqueles coletivos que não estão afetados por essa exclusão. Mesmo para esses coletivos há muito o que refletir. Previamente, vamos falar sobre a neutralidade ou não das TIC para, em seguida, comentar os usos que potencializam os processos mentais superiores e aqueles que estão baseados em processos mecânicos, repetitivos e de baixa complexidade. Para iniciar essa discussão analisaremos, ainda que brevemente, o processo de armazenamento de dados, por exemplo, em um computador.

O computador armazena dados de forma binária. Essa é uma característica construtiva, não se pode fazer de outra forma. Foi projetado para cumprir essa função (Bautista, 1998). O que significa isso? significa que qualquer fenômeno que ocorra na natureza de forma repetitiva, obedecendo a alguma lei natural, que tenha resultados esperados e que se possa medir (além de outras características da mesma natureza) pode ser representado através de um sistema binário e, em conseqüência, compilado. Ao contrário, os que não possam ser representados dessa forma, não poderão ser armazenados em um computador. O problema é que nossas dimensões internas de humanos não obedecem a essas leis naturais, não são resultados repetitivos, portanto não se encaixam no primeiro caso. Dessa forma, não podem ser guardados por um computador. Nossas características intrínsecas como as emoções, intuições, os valores, os símbolos, não podem ser codificados binariamente (Bautista, 1998).

Nesse contexto, a medida que se expande o uso não crítico do computador, da internet e de outras TIC, algumas características humanas vão ficando relegadas, pois não podem ser representadas por elas. Pouco a pouco, começamos a pensar que o que não pode ser representado no mundo dos computadores não existe, ganham força pensamentos do tipo faço clic, logo existo, que trazem implícita a idéia de que quem não faz clic está à margem da sociedade. Conforme destacado, isso representa a perda de valores próprios de nossa espécie. O que é mais grave é que a perda desses valores não ocorre por acaso. É parte integrante das funções das tecnologias na sociedade - já mencionadas na segunda seção deste trabalho, aplicadas ao âmbito educativo (Bautista, 1998):

file://C:|Documents and Settings\AdministradorlMeus documentos\Minhas Webs\NED... 28/8/2008 
a) Transmitir conteúdos disciplinares do currículo (comprimindo o tempo e o espaço).

b) Individualizar as relações de comunicação no processo ensino-aprendizagem.

c) Favorecer o controle e a direção ou governabilidade dos centros escolares.

Essas funções cumprem o papel de implantar os valores inerentes à globalização econômica nas pessoas a partir do próprio processo formativo. A individualização, por exemplo, é uma característica intrínseca dos computadores. A relação homem-máquina foi projetada para ocorrer univocamente através do teclado e, posteriormente, do mouse. Com certeza, isso contribui para que o usuário depois de certo tempo passe a entender o mundo a partir de si mesmo e para ele mesmo. Tudo que se tem que fazer depende do próprio indivíduo, portanto não lhe interessa os demais, da mesma forma que aos demais não lhes interessa os outros indivíduos, cada um se basta. Dessa forma, se os alunos crescem física, intelectual e psicologicamente vivenciando experiências individualizadoras, no futuro tais princípios farão parte de seus referentes de normalidade nas ações e nas valorações que façam (Bautista, 1998), portanto não temos o direito de ser ingênuos e pensar que as tecnologias são neutras.

Essa realidade traz muita complexidade aos usos das TIC destinados a contribuir ao desenvolvimento e formação de seres humanos mais autônomos, que preservem os traços e valores da espécie como a solidariedade, as emoções e a sensibilidade estética. É difícil conciliar essas características potencializadas pelo computador com o desenvolvimento da responsabilidade social e do pensamento coletivo. Entretanto é possível. Evidentemente, as TIC podem ser utilizadas nos processos educativos tanto para desenvolver processos mentais superiores - atividades que potencializem a capacidade de refletir nos estudantes (uso mais nobre e desejável), como para tarefas de baixa complexidade, mas que fazem parte dos conhecimentos necessários para que o indivíduos possam movimentar-se na sociedade mediatizada pelas tecnologias.

Infelizmente, hoje em dia, não existe equilíbrio entre esses empregos. Prevalece o uso meramente transmissor dessas tecnologias. Isso não ocorre somente pelas características dos equipamentos. $O$ problema é que desde a administração educativa, da gestão dos centros e do professorado se compram e utilizam softwares empacotados, fechados e prescritivos.

Como citamos três níveis distintos do sistema educativo, aproveitamos para falar um pouco de seus papéis e possibilidades. Inicialmente, a administração escolar, ao nível da administração de um país, existe para contribuir para a consecução dos objetivos "definidos" pelos governos nacionais. O problema é que esses objetivos, cada vez mais, deixam de ser definidos internamente nos governos e passam a sê-lo desde fora, desde o mercado, a quem interessa o uso de recursos que potencializem seu próprio crescimento em nome da manutenção do vigor econômico. Desta forma, é difícil introduzir alguma mudança significativa a partir dessa instância educativa. Isto não significa que os que trabalhamos em educação e a sociedade em geral devamos isentar o nível governamental dessas responsabilidades, entretanto é necessário ter clareza acerca da realidade vigente.

Temos os outros espaços: a gestão e o professorado (e o pessoal técnico- administrativo) dos centros educativos. Desde essas esferas há algumas dificuldades (Henrique Moura, 2003) mas, apesar delas, as percebemos como meio viável para uma tomada de consciência (Freire, 1999) que contribua à consecução de mudanças necessárias ao sistema educativo.

Para tanto, é necessário, como ponto de partida, que haja um reconhecimento recíproco de 
legitimidade e se concretize uma aliança entre esses segmentos e entre eles e a sociedade na perspectiva do diálogo social anteriormente mencionado, cujo objetivo deve ser o de proporcionar uma educação de qualidade à população. Uma educação reflexiva ao mesmo tempo que forma para o mundo do trabalho. Uma formação que confira aos estudantes os elementos necessários à inclusão sociolaboral.

Evidentemente, existem muitas variáveis externas aos centros (algumas já discutidas neste trabalho) sobre as quais não se tem o controle e que são barreiras à consecução desse objetivo. Mas também é verdade que muitas atividades podem ser desenvolvidas tendo o centro educativo como base, as quais podem resultar em mudanças efetivas na direção apontada.

No caso específico das TIC é possível, por exemplo, utilizar as câmaras de vídeo e os videocassetes para gravar elementos do processo ensino-aprendizagem e depois utilizar na reflexão dos próprios professores. Outra possibilidade é a análise do conteúdo dos discursos de representantes de órgãos do poder, de empresários, de sindicalistas, de associações de classes e comunitárias, de ONG's, entre outros, com o objetivo de verificar em nome de quem se está falando e a quem vai beneficiar cada discurso.

Em Química e Física pode-se fazer uma reflexão (explorar, inclusive, na elaboração de problemas) a partir de recortes de jornais, revistas, artigos encontrados na internet ou em outras fontes de informação, sobre a problemática da geração da energia no planeta, suas implicações ambientais, as causas que resultam na elevação dos preços dos combustíveis, entre outros.

$\mathrm{Na}$ Matemática é possível calcular as taxas de lucratividade de empresas (inclusive as vinculadas às TIC) de telecomunicações, bancos ou comércio eletrônico, por exemplo. A partir da Biologia pode-se analisar o significado da decodificação do genoma humano e suas implicações para as futuras gerações.

Evidentemente, seria possível descrever grande quantidade de usos mais nobres das TIC's e que conduzem alunos e alunas a uma reflexão coletiva, mas essa é tarefa de cada grupo, de cada coletivo, de cada instituição, decidir sobre o que é mais importante, mais significativo para eles mesmos (Bautista, 1994 a e b). O importante é que saibamos e estejamos convencidos de que é possível fazê-lo.

Também é preciso esclarecer que não queremos menosprezar o uso que predomina hoje em dia, orientado muito fortemente às funções instrumentais dentro de cada disciplina, principalmente no caso daquelas correspondentes às áreas de formação profissional. Esse uso é indispensável porque é exigido para que o indivíduo possa se inserir na atual sociedade. Além disso, corresponde a uma característica intrínseca das instituições de formação profissional, principalmente, as que atuam predominantemente na área tecnológica. Entretanto, queremos deixar muito claro que esse tipo de uso, ainda que reconhecidamente necessário, não é suficiente quando se tem por objetivo a formação integral do cidadão.

A postura aqui defendida também reclama por mudanças profundas nas instituições de formação do professorado. São transformações difíceis, mas possíveis. Há necessidade de mudar as próprias estruturas e seus sistemas de relações no sentido de potencializar o desenvolvimento de projetos e ações integradas por profissionais de distintos campos do saber, ou pelo menos (como um primeiro passo), dentro dos próprios departamentos.

Sem que isso ocorra não se pode avançar na formação do professorado na direção de atender aos perfis requeridos atualmente e no futuro, pois não entendemos que seja possível formar um profissional docente preparado para atuar de forma inter e transdisciplinar a partir de um modelo individualista e disciplinar e, portanto, de escassa comunicação (pessoal e profissional) entre seus membros. 


\section{REFERÊNCIAS}

ACCINO, J. A. El Silencio de los corderos sobre las tecnologías de la información y la educación. Disponível em http://www2.uca.es/HEURESIS/heuresis99/v2n3.htm. Acesso em 06/03/00.

BAUTISTA, A. Tecnocracia y romantismo. IN: Revista Cuadernos de pedagogía. Madrid: 1994a.

BAUTISTA, A. El papel de los intelectuales y la no neutralidad de la tecnología: razones para unos usos críticos de los recursos de la enseñanza. IN: Revista de educación, no 303. Madrid: 1994b.

BAUTISTA, A. Tecnología, mercado y gobernabilidad: un trinomio interactivo en la enseñanza del segundo milenio. IN: Revista complutense de educación, vol 9, n.ำ 1. Madri: 1998.

CABELLO, M. J. Aprender para convivir: concepciones y estrategias en educación de personas adultas. IN: Revista diálogos, vol 14. Madri: 1998.

TELLS, M. La sociedad red: la era de la información, vol. I. Alianza. $1^{a}$ Ed.. Madri: 1997.

CENTRO FEDERAL DE EDUCAÇÃO TECNOLÓGICA DO RIO GRANDE DO NORTE. Projeto de reestruturação curricular. Natal: CEFET-RN, 1999.

CEFET-RN, 2003.

Redimensionamento do projeto pedagógico do CEFE-RN: ponto de partida. Natal:

CHOMSKY, N. e DIETERICH, H. La Aldea global. 4ª Ed.. Tafalla: Txalaparta, 1999.

DIEESE. Desemprego no Rio Grande do Norte: visão de empresários e trabalhadores. $1^{\text {a }}$ Ed.. Natal: DIEESE / RN, 2002.

DIETERICH, H. Globalización, educación y democracia. 4ª Ed.. IN: La Aldea global. Tafalla: Txalaparta, 1999.

DOLLFUS, O. La mundialización. $1^{\text {a }}$ Ed.. Barcelona: Edicions bellaterra, 1999.

FREIRE, Paulo. Conscientização. Teoria e prática da libertação. 3ª Ed.. São Paulo: Centauro, 1980.

FRIGOTTO, G. A Produtividade da escola improdutiva. 5a Ed.. São Paulo: Cortez,1999.

GARCíA, J. A. Educación y formación para el nuevo milenio: el caso de los nuevos yacimientos de empleo. IN: Formación y empleo: enseñanza y competencias. $1^{\text {a }}$ Ed.. Granada: Editorial comares, 2000.

HENRIQUE MOURA, D. La Autoevaluación como Instrumento de Mejora de Calidad: un Estudio de Caso (El Centro Federal de Educação Tecnológica do Rio Grande do Norte / CEFET - RN / Brasil). Madri: Tese de doutorado defendida junto ao Departamento de Didática e Organização Escolar da Universidade Complutense de Madri, 2003.

LLAMAS, J. M. Coronel. Organizaciones escolares. Nuevas propuestas de análisis e investigación. $1^{\mathrm{a}}$ Ed.. Huelva: Universidade de Huelva/Serviço de publicações, 1998.

\section{[1] Tecnologias da informação e da comunicação}

[2] Este texto foi produzido originalmente em espanhol com o título "Reflexiones sobre tecnología, sociedad y educación" (Henrique Moura, 2000) como parte dos trabalhos acadêmicos do Seminário de doutorado "El desarrollo tecnológico en la formación del profesorado", na Universidade Complutense de Madri, no período letivo 1999/2000. Parte do texto original, devidamente traduzido, também integra o documento "Redimensionamento do projeto pedagógico do CEFE-RN: ponto de partida" (CEFET-RN, 2003). Esta versão atual em português incorpora alguns acontecimentos e bibliografias posteriores ao documento original.

[3] Professor do Centro Federal de Educação Tecnológica do Rio Grande do Norte - CEFET-RN. Engenheiro Eletricista. Doutor em Educação.

[4] Também é necessário reconhecer que essas fronteiras (atividades primárias, secundárias e terciárias) são cada vez mais tênues e indefinidas 
